\title{
Revista Brasileira de Estudos da Presença
}

\section{Estudos da Presença: prolegômenos para a pesquisa das práticas performativas}

\author{
Gilberto Icle \\ Universidade Federal do Rio Grande do Sul
}

\begin{abstract}
RESUMO - Estudos da Presença: prolegômenos para a pesquisa das práticas performativas - Este texto se ocupa em apresentar algumas notas sobre a maneira por intermédio da qual os Estudos da Presença se circunscrevem do ponto de vista epistemológico. Apresenta-se o contexto de pesquisa universitário no qual essa perspectiva está inserida e o modo autorreferencial de pequisar as práticas performativas. Discute-se a presença no trabalho do performer e sua relação com o significado para delimitar um campo de problematização sobre a insuficiência da interpretação como modo único de acesso ao conhecimento. Propõe-se, a partir de Michel Foucault e Hans Ulrich Gumbrecht, outros modos de pesquisa para as práticas performativas.
\end{abstract}

Palavras-chave: Estudos da Presença. Performance. Práticas performativas. Presença. Pesquisa.

\begin{abstract}
Studies on Presence: prolegomena for the research onperformative practices - Thistext presents a few notes about themanner through which the Studies on Presence define and delimitthemselves from an epistemological point of view. It presentsthe university context of the research to which this perspectivebelongs and the self-referential mode of studying performativepractices. It also discusses presence in the work of performers andits relation to meaning in order to delimit a field ofproblematisation on the inadequacy of interpretation as the only wayfor having access to knowledge. We propose, from Michel Foucault andHans Ulrich Gumbrecht, other modes of research on performative practices.
\end{abstract}

Gilberto Icle, Estudos da Presença: prolegômenos para a pesquisa das práticas performativas

R.bras.est.pres., Porto Alegre, v.1, n.1, p. 09-27, jan./jun., 2011.

Disponível em http://www.seer.ufrgs.br/presenca 
Keywords: Studieson Presence. Performance. Performative practices. Presence. Research.

RÉSUMÉ - Études de la présence: prolégomènes à la recherche sur les pratiques performatives - Ce texte propose une réflexion autour de quelques notions à partir desquelles les études de la présence peuvent être circonscrites d'un point de vue épistémologique. Présentant le contexte de recherche universitaire dans lequel cette démarche s'inscrit, l'auteur décrit le fonctionnement autoréférentiel propre aux recherches sur les pratiques performatives. Il s'interroge notamment sur la présence du performer et sa relation avec la construction du sens, mettant en exergue l'insuffisance de l'interprétation comme seul moyen d'accès à la connaissance. À partir des écrits de Michel Foucault et de Hans Ulrich Gumbrecht, l'auteur envisage enfin d'autres approches possibles des pratiques performatives.

Mots-clés: Études de la présence. Performance. Pratiques performatives. Présence. Recherche.

Silêncio. Pode a palavra parar de interromper o silêncio? Pode o silêncio atravessar os corpos que se oferecem ao olhar de outros corpos? Podem as práticas performativas tocar o silêncio? Lá, onde obra o silêncio, na calma retumbante de algo não semiotizado, não significado, não envolvido pelas ganas da palavra; lá, existe performance? Presença tênue, incipiente existência, efemeridade de um gesto, de um movimento; tratar-se-ia de um mundo, de uma dimensão, de uma vontade de calar?

Este texto pretende aduzir alguns prolegômenos, espraiar ideias, colocar na berlinda algumas verdades: suspender os efeitos dos significados, como única tarefa e caminho para pesquisar as práticas performativas. Tarefa hercúlea que este texto, entretanto, não pode levar a cabo, senão, no máximo, apontar algumas questões. Parciais, lacunares e temporários esses Estudos da Presença têm o objetivo apenas de alargar aquilo que fazemos nas pesquisas das práticas performativas, pensar, nada mais.

Não se trata, portanto, de uma nova disciplina, tampouco de um novo método que viria a revolucionar a pesquisa nas Artes Cênicas, mas, apenas, um olhar particular que este artigo pretende esquadrinhar no intuito 
de circunscrever essa perspectiva e a oferecer como possibilidade de pesquisa.

Seria possível não dizer, (re)encontrar o silêncio?

\section{Um Contexto de Pesquisa, uma Perspectiva}

O contexto universitário brasileiro e a formação dos profissionais das artes do espetáculo vivo no Brasil são bastante peculiares. Em nosso país, os conservatórios de formação de atores são raros. Os atores - ao menos um número considerável deles - são formados nos próprios grupos teatrais ou, o mais comum, nos cursos de graduação universitários. O mesmo se dá com os diretores, os cenógrafos e os professores de teatro para as escolas de ensino fundamental e médio - formação essa do professor que não existe em muitos países. Com efeito, no Brasil, os cursos de graduação são híbridos, eles formam profissionais que vão atuar num mundo do trabalho amplo: como profissionais do espetáculo, mas, também, como aqueles que vão seguir carreira na pesquisa acadêmica, nos cursos de mestrado e doutorado, ou seja, como pesquisadores.

Esse hibridismo dos cursos de formação superior em artes cênicas no Brasil implica que os professores das universidades tenham, em muitos casos, um perfil específico, qual seja: professores-pesquisadores-artistas do espetáculo vivo. A pesquisa que esse tipo de professor realiza é, muitas vezes, ligada a sua atividade profissional como ator e/ou diretor de teatro.

É nesse contexto universitário que emergem, nos últimos anos, um considerável número de pesquisas que tomam o trabalho artístico do próprio pesquisador como lócus de investigação. Os Estudos da Presença, como veremos adiante, se circunscrevem justamente na necessidade de pensar formas, maneiras e caminhos para este tipo de pesquisa: a investigação dos processos de criação das práticas performativas.

\section{Autorreferencialidade}

É por isso que a pesquisa que se orienta nos Estudos da Presença tem origem e encontra termo nas atividades artístico-investigativas. Por isso, as pesquisas em Estudos da Presença possuem - em sua maioria - um 
caráter autorreferente, pois elas começam na análise e reflexão do trabalho artístico do próprio pesquisador sem que isso seja um impeditivo para uma suposta objetividade científica a ser perseguida -, ainda que essa modalidade, a de pesquisar a si mesmo, não seja a única possibilidade para aqueles que obram em torno dos Estudos da Presença.

Assim, uma das primeiras questões epistemológicas que se impõe aos Estudos da Presença é saber se essa autorreferencialidade implica uma maneira diferente de fazer teatro, dança ou performance. É evidente que criar performances, sabendo que elas são objeto de uma pesquisa, implica um trabalho que não se equipara ipsis literis ao de outros artistas que não têm a pesquisa como objetivo de trabalho, pois o teatro, a dança ou a performance realizados por um grupo de pesquisadores-atores tem suas especificidades.

De qualquer forma, o mais importante neste texto será discutir a posição de pesquisador quando esse é objeto de pesquisa. Assim, existe um eu pesquisador que se confunde com um eu pesquisa. Nesse caminho, não pode ser estranho dizer que é do meu próprio trabalho que se nutre a pesquisa que realizo e que tem nos Estudos da Presença um ancoradouro. O leitor verá que a partir de agora este texto tornará evidente esse $\mathrm{eu}$ como narrador das ideias aqui apresentadas, propositadamente marcando um território político que circunscreve uma posição e uma concepção frente ao que se chama pesquisa. Entretanto, aqui não obram sujeitos completamente soberanos, tratar-se-ia, antes, de um sujeito cindido, partido, ao modo foucaultiano, que antes de ser produtor de discurso é, também, o resultado desse. Em resumo, considera-se aqui um eu atravessado de muitos eus, modulado na sua vontade, disperso na espessura da linguagem, falamos, então, de práticas que se constituem na "dispersão do sujeito" (Fischer, 1999, p. 43). Eu próprio, inclusive, sou ator e diretor de teatro e mantenho uma companhia teatral desde 1992 que é objeto de minha pesquisa. Esse trabalho, assim, não é apenas resultado de uma decisão soberana, mas fruto de um emaranhado discursivo que possibilita sua existência. 
Essa companhia se chama Usina do Trabalho do Ator e é composta por colegas professores da Universidade que atuam como atores e pesquisadores. $\mathrm{O}$ trabalho que fazemos na companhia tem reverberação nacional e não se trata apenas de um laboratório que faz experimentos pontuais, mas de um grupo com produção artística reconhecida e que mantém espetáculos profissionais que cumprem temporadas e fazem turnês por todo o país.

Mas a autorreferencialidade própria a boa parte do que chamo Estudos da Presença não visa unicamente a uma divagação subjetiva em relação ao próprio trabalho artístico. Esse caráter autorreferente visa, ainda, a fugir dos hábitos mais comuns na pesquisa nas áreas de teatro no Brasil, que tiveram sua origem e suas trajetórias fortemente marcadas pela linguística, pela semiótica e pelos estudos literários; abordagens que sistematicamente deixaram de fora os processos de criação para se ocupar das obras prontas e tidas como objetos fixos.

Essa operação é delicada e um conjunto de problemas de ordem epistemológica decorre de tal empresa. Para mim, e na perspectiva do que chamo Estudos da Presença, existe uma diferença de estatuto entre a pesquisa durante o processo de criação artística e a pesquisa acadêmica: esta última implica na construção de problematizações de ordem teórica, ao passo que a criação artística produz questões da ordem da prática. Eu não separo totalmente criação artística de pesquisa sobre a criação artística, no entanto, elas não coincidem em absoluto. Há para mim uma diferença importante. Eu não tomo, portanto, a criação artística como pesquisa. Isso porque a própria instauração da obra não é condição suficiente - embora necessária - para a pesquisa; como instauração, como uma poética, como um fazer-se e uma reflexão durante o próprio processo, ela (a criação da obra, ou melhor, o seu processo) constitui o modus operanti das artes, experiência e prática dada a todo artista.

Ao contrário, eu considero a pesquisa do processo de criação, uma pesquisa sobre o processo. Ainda que elas funcionem de forma complementar e que existam interferências e diálogos entre elas, existe sempre, para 
mim, uma decalagem temporal: a pesquisa acadêmica (científica se preferirem) exige um intervalo de tempo que a coloca sempre após o processo criativo. A criação, por sua vez, exige uma exclusividade, ela requer uma absorção durante o processo que impede um raciocínio mais linear, que seria exigência da pesquisa acadêmica. Em adição a isso, diferentemente das vertentes semióticas clássicas, que se ocupam exclusivamente do produto pronto, o que interessa aos Estudos da Presença é justamente compreender o processo de criação.

Nesse caminho, seria perigoso pensar a separação entre teoria e prática de forma evidente e necessária, ao contrário, como veremos em breve, tais relações são muito mais complexas. Pois o objetivo último da pesquisa acadêmica encontra o da criação, parafraseando Foucault (1984), trata-se de pensar o impensado, trata-se de pensar diferente do que se pensava.

É a partir dessa perspectiva, formulada por Foucault, que a pesquisa sobre a presença que tenho desenvolvido toma uma acepção de verdade como um jogo da linguagem. A verdade não é a substância do mundo, tampouco a construção de sentidos dados ao mundo pelo sujeito, mas um jogo do dizer no qual prática e discurso não possuem delimitações e não constituem um par separável. A partir dessa concepção de verdade, a pesquisa, para mim, não pode responder o que são as coisas do mundo, mas mostrar, descrever, de que maneira os homens (e as mulheres) se ocuparam em tornar determinados objetos do pensamento importantes para determinados grupos sociais, em determinadas épocas. Cabe responder, em contrapartida: como determinadas ideias se tornaram hegemônicas em detrimento de outras? Como algumas práticas discursivas puderam tornar determinados objetos do pensamento normativos para nós, ou seja, objetos que devemos e precisamos pensar?

Foucault, portanto, constituiu um primeiro, mas não exclusivo, apoio teórico, na medida em que oferece algumas ferramentas teóricas para a constituição dessa abordagem de pesquisa que nomeei como Estudos da Presença. 


\section{Perguntar sobre a Presença}

Eu começo evitando a pergunta mais óbvia: o que é a presença? Questão que seria deveras inócua e órfã de respostas. Ao invés disso, eu prefiro perguntar: como a presença se tornou para nós uma verdade tão importante e pulsante? De que maneira a noção de presença nos subjetiva, nos engendra e nos forma como sujeitos atores que precisam e devem estar presentes? Como a presença, por sua vez, configura uma tentativa de minimização da força de atração que a racionalidade moderna nos legou, formando um espaço de possibilidade da experiência para além dos significados?

A acepção corrente de presença no discurso teatral brasileiro faz alusão a uma qualidade da atuação. Evidentemente, nessa mesma formação discursiva, a palavra presença possui sentidos correlatos, complementares e que, por diferentes meios, fazem conexão com a ideia de presença do ator. Podemos pensar a presença como estar em presença de alguém no sentido espacial do termo ou na sua dimensão temporal, quando se está no presente.

A presença, ainda, pode fazer alusão a algo invisível ou desaparecido que se torna presente. Assim, objetos, lugares, seres podem ter uma presença, a presença de algo invisível.

Quando empregamos a palavra para designar a qualidade da atuação, de alguma forma, a empregamos com todos esses sentidos e mais alguns. Ela se confunde com a própria atuação, pois as práticas performativas não são outra coisa, senão as artes da presença. É preciso estar em presença do público para fazer acontecer o que chamamos de teatro, dança, espetáculo, performance. Por isso, a presença, paulatinamente, começa a ser empregada, não apenas como qualidade, mas também como natureza da atuação do performer. Qualidade e natureza que se hibridizam na busca do performer.

$\mathrm{O}$ ator deve ser presente para ser ator, rezam as práticas discursivas do nosso tempo. Como ator presente ele se configura ator, se dá a ver de forma qualificada e comprova a natureza de sua arte.

$\mathrm{Na}$ França, o termo presença foi utilizado pela primeira vez, para se referir ao trabalho do ator, pelo 
crítico Francis Ambrière, “[...] que o emprega nos seus artigos entre 1945 e 1948" (Farcy, 2001, p. 14). Entre nós, ela produz cada vez mais perguntas e lacunas, pois se trata, sem dúvida, de uma noção de difícil delimitação, de caráter fugidio e reativa a definições.

Seja como for, ela provém de um imaginário indefinido sobre a atuação, sobre a performance. Com efeito, ela indica uma sensação de algo que escapa à palavra, algo que não cabe na linguagem. Tratar-se-ia de um não sei o que - que tal ou tal ator aciona. Ela implica assim uma relação. Estar em presença de alguém significa ao menos duas pessoas, não se pode estar presente ou ter presença, no sentido teatral, quando se está sozinho.

Essa qualidade quase misteriosa dada pela enunciação: um não sei o que, deriva de um sentimento igualmente amalgamado, de uma vontade de descrição sempre adiada, de uma tentativa de captação sempre inacabada e de um comentário sempre interrompido que é próprio das práticas performativas. Mistério que tende, em muitos casos, ao misticismo e à idealização.

Todas essas sensações mal formuladas, próprias da nossa experiência como público, dizem respeito àquilo que os atores nos dão como experiência e que traduzimos como um fogo, uma irradiação, uma mágica vibração, um magnetismo, uma aura.

Isso indica que a presença não é senão uma experiência de presença partilhada. Algo que se localiza na interação, portanto não podemos falar da presença em si, mas de uma experiência que compartilhamos quando somos performers ou quando assistimos a uma prática performativa.

Não há, assim, por que falar na natureza da presença ou na sua essência, a presença é sempre um movimento. E como experiência em movimento, ela supõe uma cultura particular que lhe confere um lugar de enunciação e um modo de percepção. Isso significa dizer que se está presente em função de uma prática discursiva que confere valor à presença, promove sua repetibilidade (o que lhe dá possibilidade de existência no plano da linguagem) e marca uma singularidade específica. Só se pode estar presente frente a um modo culturalmente 
aceito de se estar presente. Não há, com efeito, uma presença universal e transcendental.

A presença é, portanto, uma construção no plano da linguagem - falamos sobre a presença e, ao falarmos repetidas vezes, criamos a possibilidade de ela existir -, não podemos perceber, entrementes, senão efeitos de presença.

O que ou quem está presente? Não sabemos dizer, não podemos descrever, podemos, no máximo, falar dos efeitos de presença (Enaudeau, 2001). Mas se a presença não é nada mais que um efeito é, também, porque ela se dá no seu correlato, a ausência. A necessária ausência que promove a presença é característica dos paradoxos da atuação, de Diderot à Kleist (Enaudeau, 2001); destarte, esses efeitos de presença implicam uma ideia que está no âmago da crise da representação no pensamento filosófico ocidental: a insuficiência do significado.

A pista do discurso teatral sobre a presença não se evade de tal problemática. Ao circunscrever o problema da presença nos "comportamentos cênicos codificados", Eugenio Barba, por exemplo, se pergunta "o que é a presença do ator?" (Barba, 1993, p. 7) e a desenvolve mostrando o paralelismo entre presença e significado.

O problema dos limites da palavra havia sido explorado por boa parte dos diretores-pedagogos do século XX, entre eles, sem dúvida, os trabalhos de Artaud e Decroux são exemplares. No caminho dessa problemática, Eugenio Barba e o grupo de pesquisadores e artistas que compõe a ISTA (International School of Theater Antropological) circunscrevem os elementos da presença em torno do paralelismo com o significado, ao cunhar o termo pré-expressividade. O nível que se ocupa da organização do bios cênico do trabalho do performer é compreendido como uma dimensão na qual o corpo cênico se constitui como lócus da presença, tendo uma experiência que não está ligada diretamente aos significados. A Antropologia Teatral propõe, com efeito, compreender a presença como uma dimensão apartada dos conteúdos semânticos que a tradição semiótica e linguística tanto haviam enfatizado. A presença seria, portanto, um modo não semântico de chamar a atenção do 
público em paralelo com a atração que os significados implicam para o público (Barba, 1993).

\section{Da Presença do Ator aos Estudos da Presença}

Aparentemente, essa visão - de entender os significados como paralelos e mesmo deslocados da experiência da presença - foi amplamente descrita e analisada por uma série de filósofos e pensadores do século XX. A crítica à interpretação emerge da discussão segundo a qual a representação - como modo operante das ciências humanas e da filosofia no ocidente - é insuficiente e lacunar para expressar a experiência humana.

Todas essas questões me fizeram realizar uma operação de pesquisa capaz de conduzir a discussão do estudo do trabalho do ator para a presença como cultura. Por esse motivo, a minha pesquisa não é uma indagação sobre o que é a presença do ator, como a presença acontece ou é vivenciada pelo ator e pelo público, mas, tomando algumas preocupações dos Estudos da Performance (Schechner, 2002) e da Etnocenologia (Pradier, 2000) de evitar os etnocentrismos, trata-se de analisar as culturas corporais a partir da descrição de determinadas práticas performativas - termo, aliás, tomado da Etnocenologia no intuito de evitar uma redução que a palavra teatro suporia, por expressar tão somente determinadas práticas.

Esse é, pois, o vínculo entre o estudo da presença e os Estudos da Presença. Há, nessa ponte entre uma coisa e outra, a preocupação de um alargamento, de uma passagem de um estudo restrito - os efeitos de presença no trabalho do ator -, para uma perspectiva mais ampla de investigação das práticas performativas.

Nessa perspectiva, a dos Estudos da Presença, a possibilidade de pensar a minimização da importância do significado se torna crucial e central como olhar por intermédio do qual as práticas performativas - e, sobretudo, a análise dos processos criativos - podem ser pensadas, analisadas e discutidas.

Assim, interpretar, dar significados às coisas do mundo, é tanto uma ordem colocada em suspenso pela crítica à interpretação na filosofia, quanto uma vontade de 
não interpretação proposta por uma diversidade de artistas da cena contemporânea.

Minimizar a força atrativa que a interpretação tem pra nós, configura um esforço dos Estudos da Presença para evidenciar a possibilidade de pensar alternativas à pesquisa das práticas performativas. Dar significado ao mundo e às coisas do mundo não é suficiente para compreender a experiência da presença, o ritmo que move e anima corpos em ação durante uma performance.

A presença, assim, configura uma dimensão esquecida de nossa cultura. Hans Ulrich Gumbrecht (2004) mostra como a era moderna se estruturou em torna da ideia de que a representação forneceria a nós os elementos por intermédio dos quais seríamos capazes de acessar o mundo, conhecê-lo, dominá-lo. A cisão (Gumbrecht, 1993) que fez disso o carro chefe de nossa compreensão está expressa na divisão entre corpo e espírito (ou mente), segundo a qual tudo se divide em profundidade (espírito ou mente) e superfície (corpo, texto).

Eu chamo, com efeito, de Estudos da Presença uma maneira específica de análise das práticas performativas. Esse tipo de análise pretende enfatizar a dimensão de presencialidade, de tangibilidade e de coisidade que tais práticas possuem, na medida em que são práticas corporais por excelência, procurando tirar a ênfase dos significados que atribuímos a elas. Assim, os Estudos da Presença se articulam - a partir da obra de Gumbrecht em torno do objetivo de evitar a interpretação como único e exclusivo acesso à verdade e ao conhecimento.

A pesquisa em Ciências Humanas e em Artes, de forma geral, historicamente, aderiu pouco a pouco à instauração do significado como procedimento único e exclusivo. Isso só foi possível graças a um etnocentrismo, travestido de logocentrismo, pois plasmar a razão no cerne da experiência humana não foi outra coisa, para nossa sociedade, senão um etnocentrismo hegemônico que, sistematicamente, anulou outras formas de relação com o mundo. Jean-Marie Pradier demonstra bem em seu notável livro La scène et la fabrique des corps (2000), como esse logocentrismo hegemônico contribuiu para que uma visão compartimentada de corpo, colocada em 
evidência pela anatomia, pudesse ajudar a gerar uma tendência discursiva do teatro ocidental, produzindo ainda hoje uma confusão entre teatro e literatura.

O Brasil, no entanto, é pleno de práticas performativas que não são literárias e formas de relação com o mundo que não encontram na razão instrumental apoio inequívoco. François Laplantine (2009) mostra bem isso ao analisar a ginga brasileira, como elemento sensível e impossível de ser apreendido pelos instrumentos da linguagem.

\section{Campo Hermenêutico}

Esse tipo de discussão só foi possível entre nós graças à crise da representação, o que desenvolveu uma crítica à hermenêutica como método de acesso à verdade e às coisas do mundo. Para esse tipo de reflexão é inevitável se reportar, uma vez mais, à voz filosófica de Hans Ulrich Gumbrecht (2004) que mostra como a cultura do significado tendeu, a partir da era moderna, a se sobrepor, na nossa sociedade, à cultura da presença.

$\mathrm{O}$ autor mostra a formação histórica do que ele batizou como "campo hermenêutico" (2004, p. 11), no qual a significação passou a ser, a partir da era moderna, a medida de todas as coisas importantes. Paradigma que se desenvolveu, de fato, pela cisão fundamental da forma de pensar ocidental que tornou opostos sujeito e objeto. A modernização dos sentidos (Gumbrecht, 1998) consistiria em uma maneira interpretativa de pensar o mundo, hábito de atribuir à significação um valor maior do que à presença. Nessa concepção de mundo, a interpretação se interpõe como o caminho mais seguro para desvendar algo que existiria além, abaixo, dentro, ou seja, numa dimensão escondida das coisas do mundo.

A hermenêutica e, sobretudo, a fenomenologia modos de pensar que atingem o máximo do campo hermenêutico - desenvolveram a ideia de que o sujeito atribui significado ao mundo e este último só existe na medida dessa atribuição. Ocorre que, nesse pensamento, a divisão sujeito-objeto é acompanhada pela divisão corpomente ou corpo-espírito. Ora, a porção do sujeito que atribui significado ao mundo é a mente, o corpo, por sua vez, é obstáculo à emergência dos significados que se dão 
em profundidade. Por isso é que a interpretação deve agir para garantir que tais significados, engendrados na profundidade do espírito humano, possam emergir a superfície (Gumbrecht, 1993).

O campo hermenêutico, portanto, implica uma valorização da profundidade em detrimento da superfície. Tudo o que é profundo e escondido teria mais valor na nossa cultura do que aquilo que é da dimensão da superfície.

Não se trata, obviamente, de dizer que a interpretação não deva ser empreendida, tampouco invalidar a sua importância para as Ciências Humanas e para as Artes, mas chamar a atenção para o fato da sua predominância: o fato de que, historicamente, a interpretação consiste num gesto em direção à modernidade (Gumbrecht, 2004).

Para compreender isso é salutar tomar o exemplo comparativo do teatro medieval e do teatro moderno. $\mathrm{Na}$ Idade Média o homem não pode ser considerado produtor de sentido, pois é Deus que o produz, assim, o próprio termo teatro é de difícil emprego para designar práticas performativas nas quais não havia uma linearidade de narrativa, tampouco havia uma separação evidente entre os atores, clowns, bufões e o público. Os corpos não eram separados por uma cortina. O teatro moderno se esforçou por anular os efeitos de presença, de tangibilidade das festas medievais e criar um teatro - nesse caso a palavra teatro se emprega melhor - que separa público e atores e que, no apogeu da sua abstração - por exemplo, em Racine -, a atenção dos espectadores é redirecionada do corpo dos atores, que recitam em semicírculo, para os personagens que eles encarnam (Gumbrecht, 2004).

A tradição medieval das práticas performativas é mantida no início da era moderna pela Commédia Dell'arte que, ao trabalhar com a ideia de personagens máscaras, marcados pela corporeidade, mais que pela narrativa fixa, não resistiu aos empenhos do campo hermenêutico e sucumbiu ao teatro cartesiano, vindo a desaparecer (Gumbrecht, 2004). 


\section{Campo não Hermenêutico}

Se o campo hermenêutico se erigiu sobre tal fundamento no pensamento de nossa sociedade, a vontade de dele fugir, também, configura uma prática discursiva amplamente descrita, sobretudo a partir dos anos 1970. Trata-se do que Gumbrecht chama de "campo não hermenêutico" (2004, p. 13). Eis a vontade de presença que não cessa de nos rodear. Ao mesmo tempo em que nosso mundo se torna cada vez mais mediado pela substituição do contato corporal pela tecnologia, nós convivemos com o desejo de restabelecer o contato entre os corpos.

$\mathrm{Na}$ história do teatro europeu a reivindicação de uma dimensão que escape aos significados e à racionalidade instrumental foi objeto de manifestações acaloradas, basta lembrar as proposições de Artaud, Decroux ou Grotowski.

Não foi senão no interior mesmo do campo hermenêutico que a crise da representação levou à desconfiança da significação como única forma de acesso ao mundo e autores tão distintos e tão ligados à hermenêutica enunciaram a possibilidade de que a presença poderia ser uma dimensão que, não anulando ou invalidando a interpretação, pudesse constituir um além, um a mais para a interpretação. Assim, de Hans-Georg Gadamer a Umberto Eco, de Judith Butler a Jean Luc Nancy, de Martin Heidegger a George Steiner, uma série de vozes vão reivindicar a atenção à presença, dando espaço para a discussão de um campo não hermenêutico (Gumbrecht, 2004).

$\mathrm{Na}$ Antropologia, a desconfiança em relação à autoridade do texto etnográfico, sublinhada por antropólogos como James Clifford, por exemplo, mediou uma transformação das noções de pesquisa, em especial, da relação do etnógrafo com o trabalho de campo. É curioso lembrar que a origem dessa virada linguística da Antropologia se fez a partir de Clifford Geertz, o pai da Antropologia interpretativa. O que ocorre é que ao dizer que o trabalho do etnógrafo era um trabalho de interpretação e, portanto, um trabalho de ficção, no sentido de que a descrição etnográfica é sempre uma construção, Geertz pôs por terra as convicções 
estruturalistas que haviam deixado de lado o sujeito para se debruçar sobre as estruturas. $\mathrm{O}$ seu trabalho possibilitou, então, que a virada linguística, acepção filosófica que sublinha a dimensão discursiva da verdade, pudesse encontrar a Antropologia. A partir daí, a noção de escrita etnográfica passa a reclamar uma polifonia de vozes e um inevitável envolvimento do pesquisador (Geertz; Clifford, 1992). A ilusão sobre uma possível objetividade é definitivamente soterrada pela ideia de que não existe um sujeito prévio ao discurso, ele é efeito de uma discursividade. Se a verdade é uma irrupção no jogo da linguagem, a própria noção de representação entra em crise. O que afinal se representa, quando se descreve uma representação social? Foucault, a essa altura, diria: “[...] eu nunca escrevi nada além de ficções" (apud Gros, 2007, p. 124).

Com efeito, a crise da representação dá origem e põe em marcha uma crítica à interpretação, esgotando as pretensões da semiótica clássica como forma interpretativa de acesso ao mundo e como descrição dos caminhos gerativos de sentido. É certo, no entanto, que não podemos prescindir da interpretação, tampouco retornar ao modo medieval de acesso ao mundo, então, como pensar o campo não hermenêutico? É justamente aí que se insere a pesquisa nos Estudos da Presença. Tratase de pensar outras formas de apropriação do mundo que possam, ainda que de maneira precária, ultrapassar as significações, evitar as interpretações puras, suspender os efeitos hermenêuticos e pôr em cheque as ilusões semióticas.

É, portanto, no interior desse campo não hermenêutico que a descrição do processo criativo pode se inscrever, na medida em que descreve determinadas formas de apropriação do mundo que resistem à força atrativa das significações. Essas formas de apropriação do mundo não dão importância exclusiva à dimensão de profundidade, mas lançam atenção também sobre a superfície. Paul Valery, diria: "[...] o mais profundo é a pele" (apud Fischer, 2010, p. 17). 


\section{Para Além da Interpretação}

Gumbrecht lembra que existem outras formas de apropriação do mundo que ultrapassam a interpretação. Ele fala em "comer o mundo" (2004, p. 86), comer as coisas do mundo, como na antropofagia. Da mesma forma, descreve o "penetrar o mundo" (2004, p. 87). A sexualidade, a agressão, a destruição são formas de fusão com o mundo ou com outros corpos. E "possuir o mundo" (2004, p. 89), como forma de misticismo, como desejo de consciência plena, na qual se tem uma possessão do mundo ou dos espíritos do mundo, trata-se de uma crença na perda de si mesmo.

Assim, os Estudos da Presença não são uma disciplina, mas uma abordagem, uma tentativa de minimizar as interpretações como única forma de análise das práticas performativas e de incluir os processos criativos no centro da discussão. Tarefa sempre provisória, é claro, mas que convida também os próprios artistas a darem voz a um tipo de pesquisa que não é a simples descrição de fatos e acontecimentos, mas uma polifonia de visões e movimentos.

$\mathrm{O}$ que os Estudos da Presença propõem como desafio é justamente ir além desses esboços mal formados dados pela análise semiótica e semiotizante. É tocar a presencialidade do sensível, fazer ver, evidenciar, colocar em desnudo a incapacidade da representação.

Trata-se de procurar justamente novos conceitos para poder trabalhar com dimensões da experiência humana que possam ser descritas como vibrações da presença. Essas vibrações, esses movimentos, só têm lugar na nossa experiência na espacialidade, elas resistem à temporalidade e à duração. Basta lembrar que os melhores momentos na nossa experiência estética como público, aqueles momentos em que nos sentimos em contato inequívoco com uma prática performativa, são momentos de tênue presença. São instantes em que nosso corpo vibra. Nossa experiência é sempre essa oscilação entre esses efeitos de presença e efeitos de significação (Gumbrecht, 2004).

As práticas performativas analisadas impõem para os Estudos da Presença a convicção de que se trata: 1) de uma vontade de presença que se manifesta para nós como 
oposição à hegemonia das significações - uma vontade de silêncio, diria Gumbrecht (2004, p. 133); 2) de que apesar da interveniência das significações, nós saboreamos os momentos de presença que são, de todo modo, sempre efêmeros; 3) que presença e significação são apenas efeitos da experiência vivida e encontram nas práticas performativas a oscilação necessária para servir de exemplo como modos de apropriação do mundo.

É certo que nos falta ainda conceitos e instrumentos para descrever a presença, pois a forma de tal empresa corresponde, paradoxalmente, à dimensão das significações. Precisamos usar as significações para invocar a experiência da presença, pois somente as significações aludem ao tempo, precisamos delas para restabelecer contato com o passado ou imaginar o futuro. A presença, ao contrário, é efeito de espaço.

Se nossa sociedade tem fome de nomear o mundo, de projetar significados em tudo o que toca ou olha, tem, também, necessidade de restabelecer os laços e contatos dos corpos e o faz por intermédio das práticas performativas, ainda que não apenas por elas. Num mundo cada vez mais mediado, substituído em tudo aquilo que as tecnologias de comunicação e informação podem simular, pensar a presença se assume como tarefa política, como ética das relações.

Os desafios que os Estudos da Presença encontram, portanto, não são poucos. Seria necessário mesmo pensálos para tentar, talvez, ultrapassar as barreiras interpretativas das análises tradicionais. Afinal, seria possível uma pesquisa das práticas performativas na dimensão da presença? Existiria alguma coisa para a pesquisa das práticas performativas além da interpretação? 


\section{Referências}

BARBA, Eugenio. La Canoa di Carta. Bologna: Il Mulino, 2001.

ENAUDEAU, Corinne. Le Corps de l'Abscence. In: FARCY, Gérard-Denis; PRÉDAL, Renè. Brûler les Planches, Crever l'Écran. Saint-Jean-de-Védas: L'Entretemps, 2000. P. 33-44.

FARCY, Gérard-Denis. Du Singulier au Pluriel. In: FARCY, Gérard-Denis; PRÉDAL, Renè. Brûler les Planches, Crever l'Écran. Saint-Jean-de-Védas: L'Entretemps, 2000. P. 13-20.

FISCHER, Rosa Maria Bueno. Foucault e o Desejável Conhecimento do Sujeito. Educação \& Realidade, Porto Alegre, Universidade Federal do Rio Grande do Sul, v. 24, n. 1, p. 39-59, jan./jun. 1999.

FISCHER, Rosa Maria Bueno. Prefácio. In: ICLE, Gilberto. Pedagogia Teatral como Cuidado de Si. São Paulo: Hucitec, 2010. P. 11-17.

FOUCAULT, Michel. História da Sexualidade 2: o uso dos prazeres. Rio de Janeiro: Graal, 1984.

GEERTZ, Clifford; CLIFFORD, James. El Surgimiento de la Antropologia Posmoderna. Barcelona: Gedisa, 1992.

GROS, Frédéric. Michel Foucault. Paris: PUF, 2007.

GUMBRECHT, Hans Ulrich. Modernização dos Sentidos. São Paulo: Ed. 34, 1998.

GUMBRECHT, Hans Ulrich. O Campo Não-hermenêutico ou a Materialidade da Comunicação. Rio de Janeiro: Universidade do Estado do Rio de Janeiro, 1993.

GUMBRECHT, Hans Ulrich. Production of Presence. Stanford: Stanford University Press, 2004.

LAPLANTINE, François. Le Social et le Sensible. Introduction à une Anthropologie Modale. Paris: Téraèdre, 2009.

PRADIER, Jean-Marie. La Scène et la Fabrique des Corps. Ethonoscénologie du Spectacle Vivant en Occident $\left(\mathrm{V}^{\mathrm{e}}\right.$ siècle av. J.-C. $-\mathrm{XVIII}^{\mathrm{e}}$ siècle). Bordeaux: Presses Universitaires de Bordeaux, 2000.

SCHECHNER, Richard. Performance Studies, an introduction. New York: Routledge, 2002. 
Gilberto Icle é graduado em Teatro, Mestre e Doutor em Educação pela Universidade Federal do Rio Grande do Sul onde é professor no Programa de Pós-graduação em Educação, no qual coordena o GETEPE-Grupo de estudos em educação, teatro e performance e, ligado a esse, a UTA-Usina do Trabalho do Ator, grupo de investigação e produção de espetáculos. É editor associado da Revista Educação \& Realidade e autor de diversos artigos no Brasil e exterior, além dos livros Teatro e Construção de Conhecimento, pela Editora Mercado Aberto; $O$ ator como xamã, pela Editora Perspectiva; e, Pedagogia Teatral como cuidado de si, pela Hucitec.

E-mail: gilbertoicle@gmail.com

Recebido em fevereiro de 2011

Aprovado em maio de 2011

Gilberto Icle, Estudos da Presença: prolegômenos para a pesquisa das práticas performativas R.bras.est.pres., Porto Alegre, v.1, n.1, p. 09-27, jan./jun., 2011.

Disponível em http://www.seer.ufrgs.br/presenca 